\title{
Pleistocene-dated biogeographic barriers drove divergence within the Australo-Papuan region in a sex-specific manner: an example in a widespread Australian songbird
}

\author{
Annika Mae Lamb $b^{1,2} \cdot$ Anders Gonçalves da Silva ${ }^{3} \cdot$ Leo Joseph $^{4} \cdot$ Paul Sunnucks $\mathbb{D}^{1} \cdot$ Alexandra Pavlova $\mathbb{D}^{1}$
}

Received: 14 June 2018 / Revised: 11 February 2019 / Accepted: 23 February 2019 / Published online: 15 March 2019

(c) The Author(s) 2019. This article is published with open access

\begin{abstract}
Understanding how environmental change has shaped species evolution can inform predictions of how future climate change might continue to do so. Research of widespread biological systems spanning multiple climates that have been subject to environmental change can yield generalizable inferences about the neutral and adaptive processes driving lineage divergence during periods of environmental change. We contribute to the growing body of multi-locus phylogeographic studies investigating the effect of Pleistocene climate change on species evolution by focusing on a widespread Australo-Papuan songbird with several mitochondrial lineages that diverged during the Pleistocene, the grey shrike-thrush (Colluricincla harmonica). We employed multi-locus phylogenetic, population genetic and coalescent analyses to (1) assess whether nuclear genetic diversity suggests a history congruent with that based on phenotypically defined subspecies ranges, mitochondrial clade boundaries and putative biogeographical barriers, (2) estimate genetic diversity within and genetic differentiation and gene flow among regional populations and (3) estimate population divergence times. The five currently recognized subspecies of grey shrike-thrush are genetically differentiated in nuclear and mitochondrial genomes, but connected by low levels of gene flow. Divergences among these populations are concordant with recognized historical biogeographical barriers and date to the Pleistocene. Discordance in the order of population divergence events based on mitochondrial and nuclear genomes suggests a history of sex-biased gene flow and/or mitochondrial introgression at secondary contacts. This study demonstrates that climate change can impact sexes with different dispersal biology in different ways. Incongruence between population and mitochondrial trees calls for a genome-wide investigation into dispersal, mitochondrial introgression and mitonuclear evolution.
\end{abstract}

Supplementary information The online version of this article (https:// doi.org/10.1038/s41437-019-0206-2) contains supplementary material, which is available to authorized users.

Annika Mae Lamb

amlamb@student.unimelb.edu.au

1 School of Biological Sciences, Monash University, Clayton Campus, Melbourne, VIC 3800, Australia

2 School of BioSciences, The University of Melbourne, Parkville Campus, Melbourne, VIC 3010, Australia

3 Microbial Diagnostic Unit Public Health Laboratory, The Peter Doherty for Infection and Immunity, The University of Melbourne, Melbourne, VIC 3010, Australia

4 Australian National Wildlife Collection, CSIRO National Research Collections, GPO Box 1700, Canberra, ACT 2601, Australia

\section{Introduction}

The relationship between environmental change and species evolution is convoluted due to the plethora of ways in which species are impacted by and can respond to change. Understanding the population processes affected by environmental change is important for informing predictive models of species' responses to future climate change. Climatic oscillations throughout the Pleistocene $(\sim 2.5-0.01$ million years ago; Ma) impacted the evolution of biota across the globe through fragmentation, displacement and extinction (Hewitt 2004). Populations surviving glacial maxima in disconnected refugia often diverged under effects of different climatic and ecological pressures and genetic drift (Avise 1998, 2000). Australo-Papua, however, remained largely free from Pleistocene glaciation and instead experienced cycles of aridity and sea-level fluctuations (Barrows et al. 2002; Byrne et al. 2008). 
Based on contemporary species' ranges and taxonomic treatments, numerous putative historical biogeographical barriers, thought to reflect rising sea levels and expanded arid areas that formed during the Pleistocene, have been mapped across mainland Australia (Ford 1987; Keast 1961; Schodde and Mason 1999). Two contemporary marine barriers to gene flow, Bass Strait (in the South) and Torres Strait (in the North), formed and dissipated repeatedly throughout the Pleistocene and now separate mainland Australia from Tasmania and the island of New Guinea, respectively (Chivas et al. 2001; Lambeck and Chappell 2001). Speciation events across several of these biogeographical barriers support their role in shaping the evolution of Australian biota (Dolman and Joseph 2015, 2016; Jennings and Edwards 2005; Lee and Edwards 2008; Mellick et al. 2014; Toon et al. 2010).

The biological influence of some Australo-Papuan barriers, that is, how they limited migration and affected local adaptation and lineage divergence, remains to be fully explored with molecular data (e.g., Torres Strait-Kearns et al. 2011; Toon et al. 2017; Canning Barrier-Lamb et al. 2018; Nyári and Joseph 2013). Moreover, earlier phylogeographic investigations of putative Australo-Papuan barriers employed exclusively mitochondrial DNA (mtDNA) markers (Joseph and Omland 2009), which are prone to the effect of selection and do not always reflect population history (Ballard and Whitlock 2004; Morales et al. 2015; Toews and Brelsford 2012). Multi-locus tests of mitochondrial-based inferences using nuclear data are called for.

Pleistocene climate change impacted the evolution of different species in different ways, depending on their ecology (Bowman et al. 2010; Byrne et al. 2008). The biogeographical barriers drove the divergence of species at different times and to different extents depending on species' gene flow limitations (Bowman et al. 2010; Dolman and Joseph 2012; Toon et al. 2010). Furthermore, aridadapted species have expanded their ranges during Pleistocene glacial maxima, contrary to the majority of other species studied, which experienced range contractions (e.g., butcherbirds; Kearns et al. 2014). Different responses to climate change can result in different temporal patterns of divergence across a barrier and also lead to different geographic patterns of population differentiation (Bryant and Krosch 2016; Peñalba et al. 2017). Temporally and spatially concordant biogeographic patterns can therefore be expected only in ecologically similar sympatric species. Further, some barriers have formed, disappeared and reformed over time, such that disconnected populations have experienced multiple periods of secondary contact. In some cases of secondary contact, gene flow can homogenize genetic variation among populations (Joseph and Wilke 2006; Kearns et al. 2014), and in others, intrinsic barriers evolved during isolation (i.e., genomic incompatibilities) can drive evolution of pre-zygotic isolation and speciation (Sunnucks et al. 2017).

In addition to changing over time, climate varies greatly across the Australo-Papuan region. Climatic differences across the region may have further driven local adaptation and divergence within some species (Lamb et al. 2018). The dynamic spatio-temporal nature of Pleistocene population splits, periods of secondary contact and climatic variation has promoted phylogeographic complexity. Furthermore, putative barriers have not always been found to be concordant with intra- or interspecific nuclear and/or mitochondrial genetic divergence, sometimes despite their concordance with phenotypic divergence (Eldridge et al. 2014; Kearns et al. 2010). Because of these complexities, more multi-locus phylogeographic research on widespread species spanning multiple climates is needed. This will aid in achieving a comprehensive understanding of how Pleistocene climate change influenced the evolution of the biota throughout the Australo-Papuan region.

The grey shrike-thrush (Colluricincla harmonica) is an ideal species in which to investigate the complex evolutionary effects of Pleistocene climate: it is widespread and common throughout Australia and eastern coastal New Guinea and divergence among its mitochondrial clades has been dated to the Pleistocene (Higgins and Peter 2002; Lamb et al. 2018). Analysis of mitochondrial sequence data throughout the Australian range found clade boundaries to be concordant with phenotypically defined subspecies ranges (Lamb et al. 2018; Fig. 1). Further, Marki et al. (2018) found that within the New Guinean range of the species, DNA sequence data from two individuals from two different regions suggested the presence of two lineages, one that has, and one that has not diverged from the Cape York Peninsula populations of Australia. However, denser sampling of the region is required to test this observation. Eight putative historical biogeographical and contemporary barriers align with mitochondrial clade and subspecies boundaries within grey shrike-thrush and so could have affected its evolutionary history: the Carpentarian, Eyrean, Canning, and Torresian Barriers, Einasleigh Uplands, Black Mountain Corridor, and Bass and Torres Straits (Fig. 1). These barriers have primarily been inferred from morphological and molecular data on bird species and have been tested in a range of other taxa (see Appendix S1 for a brief review).

Here we use multi-locus phylogeography to test whether the barriers mentioned above have had different effects on population diversification and mitochondrial lineage divergence within the grey shrike-thrush. Specifically, we (1) test for congruence between patterns of nuclear genetic differentiation and those based on phenotypically defined subspecies ranges (Schodde and Mason 1999), mitochondrial 
Fig. 1 The ranges of the currently accepted grey shrikethrush subspecies: bluestrigata, red-harmonica, purple-superciliosa, greenbrunnea and yellowrufiventris, and contemporary and putative historical biogeographic barriers and relevant geographic regions (Schodde and Mason 1999). The grey shrike-thrush mitochondrial ND2 tree topology adapted from Lamb et al. (2018) is also shown (same colours apply); here we considered the King Island and Tasmanian lineages as one because their ranges overlap

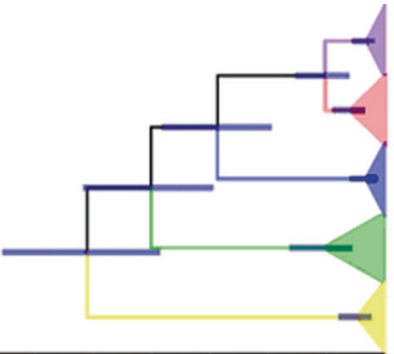

$\begin{array}{llllll}1.50 & 1.25 & 1.00 & 0.75 & 0.50 & 0.25\end{array}$ Millions of Years Ago

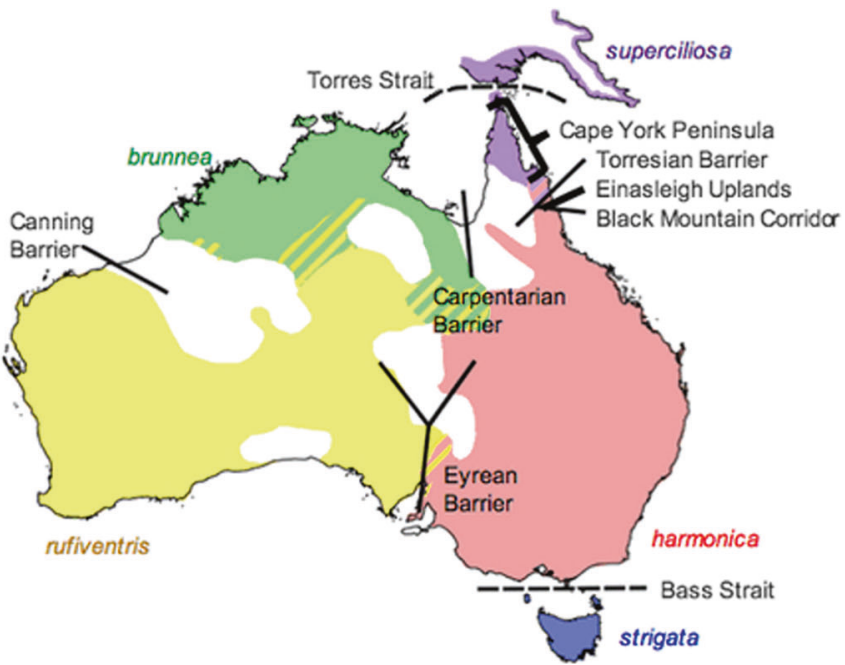

Central Province (see Appendix S2 in Supporting Information). The sex of the grey shrike-thrush individuals was inferred from phenotype and/or molecular sexing (Appendix 2). A Qiagen extraction kit was used to extract the genomic DNA from 19 PNG and Cape York Peninsula tissue samples from the Australian National Wildlife Collection (ANWC, CSIRO, Canberra), following the manufacturer's instructions. These 19 individuals were sequenced for the ND2 locus following the approach in Pavlova et al. (2014), augmenting the total ND2 dataset to 189 sequences (Appendix S2). A subset of 69 individuals, representative of the entire range of the species, was further sequenced for one Z-linked and five autosomal intron loci (see Appendix S2 for a list of sequenced individuals and Appendix S3 in Supporting Information for amplification and sequencing details). The Phase 2.1 algorithm (Stephens and Donnelly 2003) implemented in DnaSP 6.11.01 (Rozas et al. 2017) was used to resolve the gametic phases of the nuclear intron sequences. For the Z-linked nuclear intron locus, only sequences from males were phased to account for hemizygosity of the Z-chromosome in females. Sequences containing double-indels could not be accurately aligned and phased and so were excluded from analyses. All sequenced loci were tested for significant deviations from linkage equilibria in each of the grey shrike-thrush populations using GENEPOP 4.2 (Raymond and Rousset 2004); for this analysis, populations were defined based on ND2 clade membership (see below) because of the tight correlation between ND2 clade and subspecies geographic boundaries. We further genotyped 170 individuals with sampling locations within Australia for 14 length-variable markers (Appendix S2): 11 microsatellite (BMC3, Cpi4, FhU2, FT25, HrU2, Pdo5, Ppi2, Ppm1, Ppm11, Ppm3, Ppm7) and 3 variable-length exon-primed-intron-crossing loci (23989, 4550s1, 24254s) that had previously been shown to be in linkage equilibria in grey shrike-thrush populations 
(Pavlova et al. 2012). Individuals from PNG were not included in these length-variable nuclear assays, because they were collected in the field after analyses of the microsatellite and variable-length exon-primed-introncrossing dataset was complete.

\section{Assessing nuclear genetic structure}

Nuclear genetic structure within the species was assessed using Bayesian clustering using tessellations in TESS 2.3.1 (Chen et al. 2007) to test whether putative biogeographical barriers, shown to be concordant with phenotypically defined subspecies boundaries and mitochondrial clade boundaries, are also concordant with nuclear genetic structure. Two analyses were run: one on length-variable marker genotypes, the other on nuclear intron sequence data (excluding the data for the sex-linked locus) in which the phased alleles at the sequenced introns were considered diploid genotypes. Individuals missing $>20 \%$ of genotypes were excluded from analyses. A BYM model was implemented with a parameter of Dirichlet allele frequency model $D=1.0$, a spatial interaction parameter $P=0.6$ and a trend degree $T=2$ (Durand et al. 2009). TESS was run assuming a range of cluster values ( $K$ from 2 to 10); for each $K, 100$ replicates of 30,000 burn-in sweeps followed by 100,000 sweeps were run. The calculated cluster probabilities of the 10 replicates with the lowest deviance information criterion (DIC) values of each $K$ were averaged using CLUMPP 1.1.2 (Jakobsson and Rosenberg 2007). The most likely number of genetic clusters was identified based on run DIC values (see Appendix S4 in Supporting Information for details). To visualize the geographic arrangement of clusters for each nuclear dataset, we mapped memberships of each individual in genetic clusters over subspecies distributions (Schodde and Mason 1999) using Quantum GIS (qGIS 2.14.3) (qGIS Development QGIS Development Team 2017). Within-locus haplotypic relationships of the nuclear intron loci were analyzed using median-joining networks (Bandelt et al. 1999) constructed in PopArt (Leigh and Bryant 2015).

\section{Estimating divergence times among mitochondrial lineages and regional populations}

Coalescent analyses were conducted to estimate the timing of mitochondrial lineage divergence and population divergence based on nuclear data to test for concordance between nuclear and mitochondrial evolution. Co-analysis of mitochondrial and nuclear DNA data using *BEAST within BEAST 2.4.7 (Bouckaert et al. 2014) was attempted but the parameters did not converge (low effective sample size (ESS) values and multimodal parameter distributions).
Mitochondrial ND2 and nuclear intron sequence data were therefore analyzed separately.

A mitochondrial phylogeny was constructed from the ND2 sequences including individuals from PNG in BEAST 2.4.7 (building on Lamb et al. 2018). The Bayesian Information Criterion implemented in PartitionFinder 1.1.1 (Lanfear et al. 2012) identified the optimal partitioning scheme of the ND2 alignment to be by codon position and the ideal models of molecular evolution to be HKY + I for position 1, TrN93 + I for position 2 and HKY for position 3. BEAST analyses were run with unlinked substitution rates and clock models but linked trees for the three partitions. Trial 100 million generation runs of BEAST were conducted using each of the coalescent tree priors and compared. The divergence times within the trees derived from these trail runs were consistent, irrespective of which coalescent tree prior was implemented. A Bayesian Coalescent Skyline plot prior (Drummond et al. 2005), which allows for complicated demographic histories (Ho and Shapiro 2011) was applied for the final analysis and a random starting tree was used. Divergence times were calibrated using ND2 clock rates estimated from the Hawaiian honeycreeper system (Lerner et al. 2011), which represents a comparable case of recent divergence ( $<2$ my) among the lineages of a passerine species: prior clock rates (mean of a lognormal distribution; range of $95 \%$ sampled rates) were set at $6.3 \times 10^{-3}\left(5.6-7.2 \times 10^{-3}\right)$ substitutions per site per million years $(\mathrm{s} / \mathrm{s} / \mathrm{my})$ for codon position one, $1.6 \times 10^{-3}\left(1.3-2.0 \times 10^{-3}\right) \mathrm{s} / \mathrm{s} / \mathrm{my}$ for position two and 5.8 $10^{-2}\left(5.2-6.3 \times 10^{-2}\right) \mathrm{s} / \mathrm{s} / \mathrm{my}$ for position 3 . Four runs of 100 million generations were conducted, sampled every 10,000 generations and checked for convergence using Tracer 1.6.0 (Rambaut and Drummond 2007). The runs were combined and thinned 10,000-fold using LogCombiner 1.8.3 (Drummond and Rambaut 2007) after discarding the first $10 \%$ as burn-in. The resulting set of trees was summarized using Tree Annotator 1.8.3 (Drummond and Rambaut 2007) to create a Maximum Clade Credibility tree visualized using FigTree 1.4.2 (Rambaut 2014) and strongly supported clades with posterior probability $\geq 0.90$ were considered distinct mitolineages.

To estimate time of population divergence, we used a species tree approach implemented in *BEAST within BEAST 2.4.7 using the sequencing data for the six nuclear intron loci. PartitionFinder was used to identify the best-fit model of molecular evolution for each locus: AB4: K80, DRD4: $\mathrm{K} 80+\mathrm{I}+\mathrm{G}, \quad$ GAPDH11: $\mathrm{K} 80+\mathrm{I}, \quad$ MUSK-I4: HKY, RI2: K80, and TGFb2: K80 + I + G. A strict clock model was implemented and the following prior clock rates were set: $1.05 \times 10^{-3}\left(0.38-2.1 \times 10^{-3}\right) \mathrm{s} / \mathrm{s} / \mathrm{my}$ for $\mathrm{AB} 4$, DRD4, MUSK-I4, RI2 and TGFb2, and $1.2 \times 10^{-3}$ $\left(0.78-1.7 \times 10^{-3}\right) \mathrm{s} / \mathrm{s} / \mathrm{my}$ for GAPDH11 (Lerner et al. 2011). The five nuclear genetic clusters identified for grey 
shrike-thrush based on TESS analysis of nuclear intron data were treated a priori as different species in this analysis (Appendix S4): Tasmania, east Australian, Cape York Peninsula and PNG, north-west and south-west/central. The Yule speciation model and continuous-linear and constant root population size model were applied to species trees (Heled and Drummond 2010). The analysis was run for four replicates of 100 million generations, and sampled every 10,000 generations. The replicate runs were combined, summarized and visualized to generate a species tree based on the nuclear intron data using the approach outlined above. It should be noted that *BEAST assumes that there is no gene flow among diverged lineages and so the presence of gene flow may have biased divergence time estimates towards more recent times.

\section{Regional population genetic differentiation, within- population genetic diversity and tests of selection or demographic changes in ND2}

We estimated differentiation among regional populations of grey shrike-thrush and across putative biogeographical barriers in Arlequin 3.5.2.1 (Excoffier and Lischer 2010) using pairwise $F_{\mathrm{ST}}$ for the length-variable marker data and $\Phi_{\text {ST }}$ for the ND2 and nuclear intron sequence data. For these analyses, individuals were assigned to populations based on their locations relative to putative barriers and compared with tests for correlations between the putative barriers and population differentiation (Fig. 1). To account for multiple comparisons $(n=56)$, a $P$-value corrected using a modified false discovery rate procedure (Benjamini and Yekutieli 2001) of 0.011 was used to determine the significance of $F_{\mathrm{ST}}$ and $\Phi_{\mathrm{ST}}$ values. Length-variable marker diversity of each population was estimated by calculating expected heterozygosity in Arlequin 3.5 (Excoffier and Lischer 2010), number of private alleles using GenAlEx (Peakall and Smouse 2006) and allelic richness in FSTAT (Goudet 2001). Sequence diversity was assessed by calculating the number of segregating sites, number of haplotypes, haplotype diversity and nucleotide diversity of the ND2 and nuclear intron sequence data in Arlequin. $\theta_{\pi}$, a mutationscaled estimate of effective population size derived from number of pairwise differences, was further estimated in Arlequin for the nuclear intron sequence dataset. The diversity indices of the nuclear intron dataset were averaged among loci to give mean diversity indices. Diversity indices of the Cape York Peninsula regional population could not be calculated for GAPDH11, because all but one of the relevant sequences showed double-indels. Tajima's $D$ and $\mathrm{Fu}$ and Li's $F$ statistic were calculated from the ND2 sequences of each regional population to test for selection and/or demographic change in DnaSP (Rozas et al. 2017).
Estimating gene flow among regional populations

Nuclear gene flow among the Australian grey shrike-thrush regional populations was estimated from length-variable markers using MIGRATE-N 3.6.11 (Beerli and Felsenstein 2001). MIGRATE-N is a Bayesian analysis that co-estimates historical (Kuhner 2009) mutation-scaled migration rates $M=\mathrm{m} / \mu$ and effective population sizes $\theta=4 \mathrm{Ne} \mu$, where $\mathrm{m}-$ immigration rate, $\mu$-mutation rate, $\mathrm{Ne}$-effective population size and 4-scalar for diploid data. The number of effective migrants per generation moving from population A to population $\mathrm{B}$ can be estimated using $\left(M_{\mathrm{A} \rightarrow \mathrm{B}} \theta_{\mathrm{B}}\right) / 4$; where $M_{\mathrm{A} \rightarrow \mathrm{B}}$ is the mutation-scaled migration rate from $\mathrm{A}$ to $\mathrm{B}$, and $\theta_{\mathrm{B}}$ is the effective population size $\mathrm{B}$. The lower and upper bounds of confidence intervals around the number of effective migrants per generation were estimated by inputting, respectively, the 2.5th and 97.5th percentile estimates of $M_{\mathrm{A} \rightarrow \mathrm{B}}$ and $\theta_{\mathrm{B}}$ into the same equation. The Tasmanian regional population was excluded from this analysis due to its contemporary isolation (supported by strong and significant differentiation; see Results) and to prevent problematic over-parameterization of the model. Among the Australian mainland populations, 12 asymmetric migration parameters were estimated. The dataset was subsampled using a random sample size of 12 (the smallest sample size for a regional population) so that an equal number of individuals was analyzed from each regional population. Analyses were run with gamma-distributed priors on $M$ (mean 0.5 ) and $\theta$ (mean 10). This low migration rate prior ensured that the Markov chains were started in regions of parameter space that are consistent with the clear mitochondrial genetic structure seen among regional populations of the species (Lamb et al. 2018). The Brownian motion approximation of the stepwise mutation model was implemented and Watterson's approximations of relative mutation rates were estimated from the data. Markov chain Monte Carlo (MCMC) analyses were run with four heated chains of temperatures $1.0,1.5,3.0$ and $1 \times 10^{6}$ for 20 replicates that each had a 500 sample burn-in and an additional 500 sample chain. Convergence of the MCMC was confirmed by unimodal and approximately normal posterior distributions and acceptance ratios between 0.2 and 0.6 .

\section{Results}

\section{Nuclear genetic structure-TESS analyses}

For length-variable marker data (collected only for Australian grey shrike-thrush individuals), four genetic clusters were identified (Appendix S4). Three of these clusters align with the geographic ranges of strigata, harmonica and rufiventris and boundaries of their respective mitochondrial clades: Tasmania, east Australian and south-west/central 

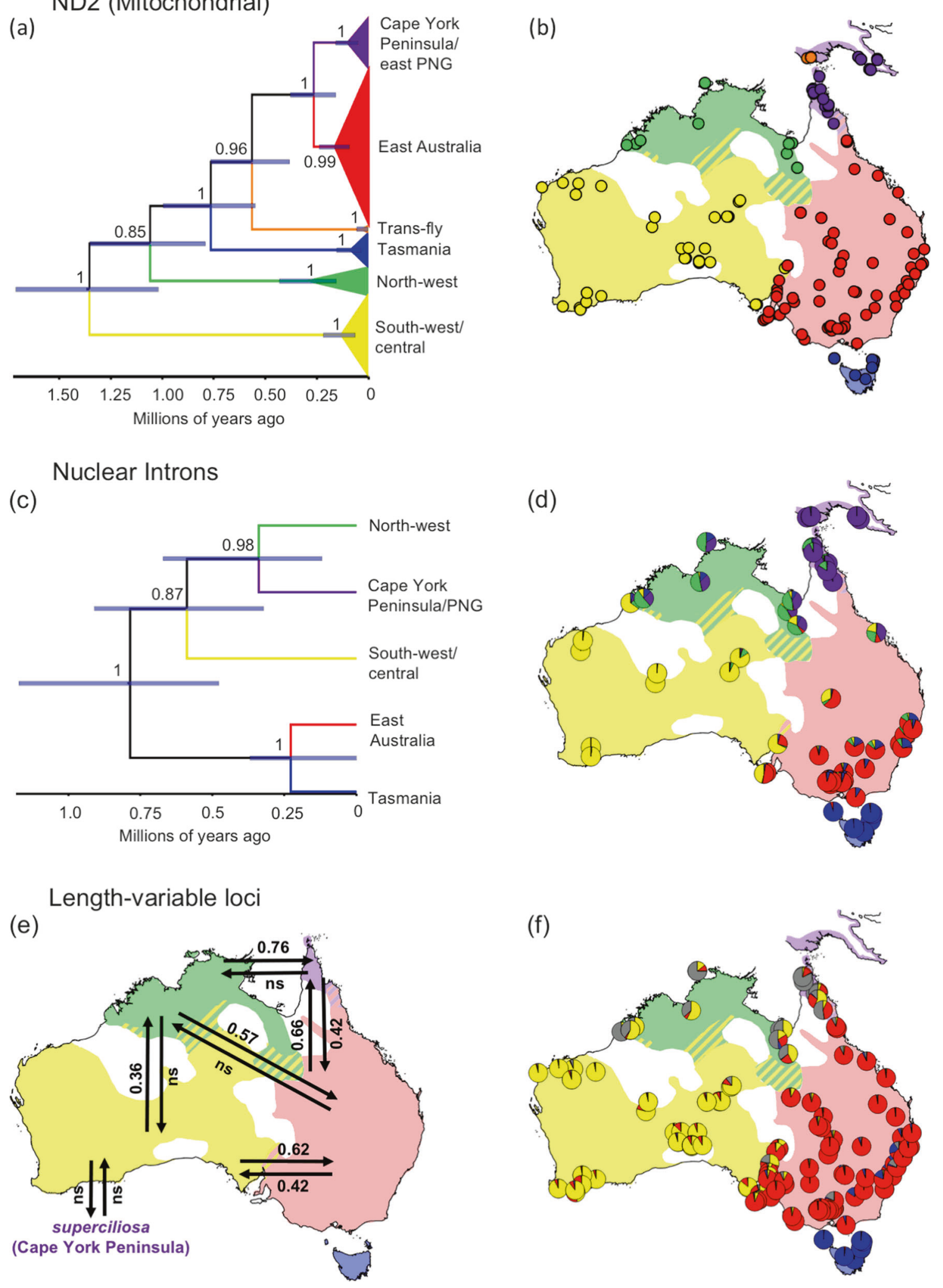

(Lamb et al. 2018) (Fig. 2f). The two northern Australian subspecies, brunnea and superciliosa, comprise the fourth genetic cluster (Fig. 2f).

For nuclear intron sequence data (collected for the Australian and PNG individuals), five genetic clusters were identified across the entire range of the species (Appendix 
Fig. 2 Individual membership to genetic clades, phylogenetic ND2 gene tree (a) and nuclear intron species tree (c) showing divergence among clades and gene flow between subspecies. Subspecies ranges are coloured as in Fig. 1. Mapped individuals in (b) are coloured by mitochondrial clade based on phylogenetic analysis of ND2 data. Pies in (d) and (f) represent genetic cluster membership probabilities identified by TESS analyses of the nuclear intron data (d) and lengthvariable marker data (f). Note that grey slices in the pies in (f) represent the genetic cluster shared by brunnea and superciliosa individuals. Map on (e) shows effective immigration rate estimates (in number of effective migrants per generation (confidence interval)) inferred by MIGRATE-N from the length-variable marker data. Where confidence intervals overlapped zero, effective immigration rates are shown as nonsignificant (ns)

S4) and each genetic cluster mainly mapped to one of the five subspecies (Fig. 2d; see Appendix S5 for nuclear intron haplotype networks). That is, a single genetic cluster mainly mapped to the distributions of the PNG and Cape York Peninsula populations.

\section{Mitochondrial gene tree}

Each of the four BEAST runs converged and combined ESS values were $>200$ for all parameters. The splitting order and divergence dates of Australian mitolineages (Fig. 2a) were consistent with those of Lamb et al. (2018) (Fig. 1; see Appendix S6 for detailed phylogeny). Consistent with Marki et al. (2018), New Guinea was found to have two mitochondrial lineages. One lineage was indistinguishable from the Cape York Peninsula lineage and included individuals from the Oro and Central PNG Provinces. Another lineage was found to be a sister to the east Australian and Cape York Peninsula/east PNG lineages, from which it was estimated to have diverged $0.38-0.76 \mathrm{Ma}$, and included individuals from the Trans-Fly region.

\section{Nuclear intron species tree}

The four *BEAST runs converged, and combined ESS values were $>200$ for all parameters. The topology of the species tree (Fig. 2c) did not match that of the ND2 gene tree (Fig. 2a). Within the species tree, the ancestor of the east Australian and Tasmanian regional populations was estimated to have diverged $0.47-1.15 \mathrm{Ma}$ from the ancestor of the south-west/central, Cape York Peninsula/east PNG and north-west regional populations. The east Australian and Tasmanian regional populations were estimated to have diverged $0.11-0.39 \mathrm{Ma}$. The south-west/central regional population was estimated to have diverged $0.32-0.90 \mathrm{Ma}$ from the ancestor of the Cape York Peninsula/PNG and north-west regional populations. The Cape York Peninsula/ PNG and north-west regional populations were estimated to have diverged $0.16-0.59 \mathrm{Ma}$.

\section{Genetic differentiation and diversity and ND2 selection in regional populations}

With one exception, regional grey shrike-thrush populations separated by contemporary or putative historical biogeographical barriers were significantly differentiated from each other at ND2, microsatellite and three or more nuclear intron loci $(P<0.011)$ (Table 1$)$. The exception was that differentiation across the Torres Strait (between Australia and New Guinea) was not significant for nuclear intron sequences.

Relative to mainland Australian populations, the Tasmanian population was consistently found to have low genetic diversity in length-variable markers, mitochondrial ND2 and nuclear intron sequences (Table 2). The PNG population also had relatively low genetic diversity in nuclear intron sequences (Table 2), but harboured two mitochondrial ND2 lineages with relatively high combined nucleotide diversity (Table 2). Effective population sizes derived from the length-variable marker dataset were similar among mainland populations (Table 2). Relative to the mainland populations, the effective population sizes of the Tasmanian and PNG populations estimated using nuclear intron sequences were low (Table 2).

Tajima's $D$ and Fu and Li's $F$ statistic estimates were significantly negative for the ND2 sequences of the southwest/central and east Australian regional populations (Table 2). Estimates for all other regional populations were nonsignificant (Table 2).

\section{Nuclear gene flow among regional populations}

Low levels of nuclear gene flow (mean effective population immigration rates $<1$ migrant per generation) were detected among the grey shrike-thrush regional populations (Fig. 2e; Appendix S7 in Supporting Information). Unidirectional gene flow was detected from north-west Australia to Cape York Peninsula and to east Australia, and from the southwest/central to the north-west regional populations (Fig. 2e). Bidirectional gene flow was detected between the Cape York Peninsula and east Australian and between east Australian and south-west/central populations (Fig. 2e). Gene flow in five other directions did not differ significantly from 0 (confidence intervals overlapped with 0; Appendix S7).

\section{Discussion}

In using nuclear and mitochondrial genetic data to assess the roles of biogeographic barriers in the evolution of a widespread Australo-Papuan songbird, the grey shrikethrush, we have generated four key findings. First, the 
geographic arrangement of nuclear genetic diversity was broadly concordant with mitochondrial genetic diversity, phenotypically defined subspecies ranges and contemporary or putative historical biogeographical barriers. Two exceptions to this were that the Trans-Fly population and the Cape York Peninsula/east PNG populations are distinguishable based on mitochondrial but not nuclear sequence data, and the Cape York Peninsula and north-west populations are distinguishable based on mitochondrial data and cluster analysis of the nuclear intron sequence data, but not cluster analysis of the microsatellite data. Second, genetic differentiation across the implicated barriers was significant for mitochondrial, microsatellite and some nuclear intron data and dated to the Pleistocene (0.01-2.58 Ma). There was one exception to this: nuclear genetic differentiation was not significant across the Torres Strait. Third, the order of population divergence inferred from mtDNA and nuclear DNA (nDNA) is not consistent, suggesting a history of sex-biased gene flow and/or mitochondrial introgression. Finally, parapatric regional populations appear to be connected by low levels of gene flow $(<1$ migrant per generation).

\section{Discrepancies between mitochondrial ND2 and nuclear intron evolution}

The timing and order of divergence events inferred from mtDNA and nDNA are not consistent. Unusually for songbirds, the grey shrike-thrush has male-biased dispersal (Pavlova et al. 2012), which can slow down population divergence at nuclear genes while maintaining divergence of the mitochondrial genome (Melnick and Hoelzer 1992). Therefore, a low level of nuclear gene flow among the parapatric Australian regional populations, which harbour different mitochondrial lineages, could be mediated by males. Differing levels of male-mediated gene flow among population pairs and female-mediated mitochondrial introgression can influence the order of apparent divergence events on nuclear and mitochondrial genomes (Ballard and Whitlock 2004; Havird and Sloan 2016; Morales et al. 2017; Toews and Brelsford 2012). Lineage sorting is expected to be slower for nuclear autosomal loci than for the mitochondrial genome because of a larger effective population size (Charlesworth 2002). Relatively rapid lineage sorting at mitochondrial loci may have resulted in the more ancient divergence among lineages at mitochondrial compared with nuclear loci seen across some barriers. However, different rates of lineage sorting cannot explain the different order of splitting events in the mitochondrial gene tree and nuclear intron species tree. For example, in two cases, sister groups that are well-supported on nuclear data, North-west and Cape York Peninsula/PNG, diverged 0.16-0.59 Ma, and East Australia and Tasmania, diverged 0.11-0.39 Ma, 
Table 2 Estimates of genetic diversity for the regional populations of $C$. harmonica and results of tests of selection/demographic change (Tajima's $D$ and Fu and Li's $F$ statistic estimates) in ND2

\begin{tabular}{|c|c|c|c|c|c|c|c|}
\hline Dataset & $\begin{array}{l}\text { Regional } \\
\text { population }\end{array}$ & Tasmanian & East Australia & $\begin{array}{l}\text { Cape York } \\
\text { Peninsula }\end{array}$ & $\begin{array}{l}\text { Papua New } \\
\text { Guinea }\end{array}$ & North-west & $\begin{array}{l}\text { South-west/ } \\
\text { central }\end{array}$ \\
\hline \multirow{7}{*}{$\begin{array}{l}\text { Length- } \\
\text { variable } \\
\text { markers }\end{array}$} & $N$ inds & 18 & 83 & 12 & - & 15 & 42 \\
\hline & $\begin{array}{l}\% \text { Polymorphic } \\
\text { loci }\end{array}$ & 35.7 & 100.0 & 100.0 & - & 78.6 & 85.7 \\
\hline & $N$ alleles/locus & 2.64 & 9.50 & 5.64 & - & 5.93 & 7.71 \\
\hline & $\begin{array}{l}N \text { private alleles/ } \\
\text { locus }\end{array}$ & 0.29 & 1.93 & 0.29 & - & 0.57 & 1.00 \\
\hline & $\mathrm{AR}$ & 2.93 & 5.52 & 5.64 & - & 5.61 & 5.38 \\
\hline & $\mathrm{He}(\mathrm{sd})$ & $0.23(0.13)$ & $0.57(0.29)$ & $0.55(0.29)$ & - & $0.53(0.28)$ & $0.52(0.27)$ \\
\hline & $\theta$ & - & 4.29 & 4.90 & - & 4.29 & 4.26 \\
\hline \multirow[t]{7}{*}{ ND2 } & $N$ inds & 18 & 84 & 15 & 16 & 15 & 41 \\
\hline & $\mathrm{S}$ & 5 & 80 & 12 & 30 & 23 & 31 \\
\hline & $\mathrm{H}$ & 6 & 37 & 9 & 6 & 12 & 25 \\
\hline & $\mathrm{Hd}$ & 0.719 & 0.903 & 0.848 & 0.808 & 0.971 & 0.955 \\
\hline & $\pi$ & 0.0015 & 0.004 & 0.0028 & 0.010 & 0.0042 & 0.003 \\
\hline & $\begin{array}{l}\text { Tajima's } D \\
\text { (P-value) }\end{array}$ & $0.151(>0.10)$ & $-2.191(<0.01)$ & $-0.860(>0.10)$ & $0.771(>0.10)$ & $-1.576(>0.10)$ & $\begin{array}{l}-1.934 \\
(<0.05)\end{array}$ \\
\hline & $\begin{array}{l}\text { Fu and Li's } F \\
(P \text {-value })\end{array}$ & $-0.252(>0.10)$ & $-3.503(<0.02)$ & $-1.209(>0.10)$ & $1.457(>0.05)$ & $-1.962(>0.10)$ & $\begin{array}{l}-2.812 \\
(<0.05)\end{array}$ \\
\hline \multirow[t]{6}{*}{$\begin{array}{l}\text { Nuclear } \\
\text { introns }\end{array}$} & $\begin{array}{l}N \text { inds mean } \\
(\min -\max )\end{array}$ & $6.2(2-7)$ & $32.2(29-33)$ & $5.7(1-7)$ & $7.7(6-8)$ & $6.2(2-7)$ & $7.5(6-8)$ \\
\hline & $\begin{array}{l}\text { S mean } \\
(\min -\max )\end{array}$ & $2.7(0-9)$ & $13.0(2-29)$ & $6.2(1-16)$ & $3.7(0-12)$ & $6.3(1-18)$ & $5(0-9)$ \\
\hline & $\begin{array}{l}\text { H mean } \\
(\min -\max )\end{array}$ & $1.8(1-3)$ & $15.2(3-32)$ & $4.4(2-9)$ & $2.7(1-5)$ & $4.7(2-10)$ & $5.2(1-9)$ \\
\hline & $\begin{array}{l}\text { Hd mean } \\
(\min -\max )\end{array}$ & $\begin{array}{l}0.263 \\
(0-0.833)\end{array}$ & $\begin{array}{l}0.703 \\
(0.461-0.966)\end{array}$ & $0.559(0.20-0.923)$ & $\begin{array}{l}0.296 \\
(0-0.525)\end{array}$ & $0.621(0.264-1)$ & $\begin{array}{l}0.550 \\
(0-0.9242)\end{array}$ \\
\hline & $\begin{array}{l}\pi \text { mean } \\
(\min -\max )\end{array}$ & $\begin{array}{l}0.0026 \\
(0-0.0123)\end{array}$ & $\begin{array}{l}0.0053 \\
(0.0009-0.0111)\end{array}$ & $\begin{array}{l}0.0035 \\
(0.0007-0.0095)\end{array}$ & $\begin{array}{l}0.0020 \\
(0-0.0039)\end{array}$ & $\begin{array}{l}0.0046 \\
(0.0009-0.0118)\end{array}$ & $\begin{array}{l}0.0031 \\
(0-0.0101)\end{array}$ \\
\hline & $\theta_{\pi}(\min -\max )$ & $0.93(0-3.83)$ & $2.39(0.48-5.45)$ & $1.90(0.2-5.63)$ & $0.87(0-2.32)$ & $2.04(0.26-5.49)$ & $1.33(0-3.14)$ \\
\hline
\end{tabular}

The number of individuals analyzed for each dataset ( $N$ inds); percentage polymorphic loci, number of alleles per locus, number of private alleles per locus, allelic richness (AR) and heterozygosity (He) of the length-variable marker data; and the number of segregating sites (S), number of haplotypes $(\mathrm{H})$, haplotype diversity $(\mathrm{Hd})$ and nucleotide diversity $(\pi)$ of sequence data are listed. Mutation-scaled estimates of effective population size calculated for the length-variable marker $(\theta)$ and nuclear intron $\left(\theta_{\pi}\right)$ data are also listed

are interspersed with other lineages on the mitochondrial tree, with divergence dating to $0.79-1.35 \mathrm{Ma}$ and $0.55-1.00 \mathrm{Ma}$, respectively (Fig. 2). Even if the mutation rate priors applied for the coalescent analyses are not appropriate for one or multiple loci, this would have resulted in consistent differences in divergence times between the mitochondrial gene and nuclear intron species trees. Thus, neither different rates of lineage sorting nor inappropriate mutation rate priors, alone or together, can explain different tree topologies derived from mitochondrial and nuclear markers. Different combinations of purifying, positive and frequency-dependent natural selection, however, can have complex effects on phylogenies (Edwards 2009). Significantly negative Tajima's $D$ and Fu and Li's $F$ statistic estimates for the mitochondrial locus indicate a selective sweep or purifying selection and/or recent population expansion in the east Australian and south-west/central regional populations. Furthermore, mitochondrial sequence variation within grey shrike-thrush has previously been associated with aridity, and a candidate amino-acid target of positive selection was identified in ND6 for the south-west/ central mitolineage through comparative analysis (Lamb et al. 2018). It is possible that climate-driven selection drove adaptive mitochondrial introgression, resulting in discrepancies between mitochondrial and nuclear DNA evolution, specific cases of which we discuss below.

\section{Evidence of biogeographical barriers driving divergence during the Pleistocene}

The Carpentarian Barrier is concordant with significant mitochondrial and nuclear DNA differentiation dated to the 
Pleistocene between the north-west and Cape York Peninsula and north-west and east Australian forms of grey shrike-thrush. Notably, clustering analysis of lengthvariable markers did not reveal a phylogeographic break concordant with the Carpentarian barrier between the northwest and Cape York Peninsula populations. The lengthvariable markers in the dataset are mainly microsatellite loci and so this is contrary to the common view that microsatellites provide greater genetic resolution than sequence data because of their relatively high mutation rate; this could be due to homoplasy resulting from limit to size changes (see Coates et al. 2009 for explanatory mechanisms). Further, mtDNA divergence between the north-west and Cape York Peninsula/east PNG lineages was estimated to be relatively ancient compared with nuclear DNA divergence. We detected nuclear gene flow from the northwest to Cape York Peninsula population. Male-mediated dispersal via the land bridges that connected northern Australia and the island of New Guinea prior to the last marine transgression $(9.7 \mathrm{ka})$ may have been sufficient to overcome some of the effect of the Carpentarian barrier on nuclear differentiation (Chivas et al. 2001; Torgersen et al. 1988; counter example in Eldridge et al. 2014). We infer that the Carpentarian Barrier drove vicariance-based phylogeographic structure of the grey shrike-thrush as seen in many, but not all, relevant species studied to date (Eldridge et al. 2014; Jennings and Edwards 2005; Joseph et al. 2011; Kearns et al. 2010, 2011; Lee and Edwards 2008; Potter et al. 2012; Schweizer et al. 2013). This, together with the variable timing of divergence across the Carpentarian barrier among species, indicates it may have had speciesspecific effects on divergence perhaps relating to dispersal ability, habitat preference and overall geographical range (Jennings and Edwards 2005; Lee and Edwards 2008; Schweizer et al. 2013; Toon et al. 2010).

The Eyrean Barrier is concordant with the substantial phylogeographic structure seen in nuclear and mitochondrial data between the east Australian and south-west/central regional forms of grey shrike-thrush. This barrier also fits Pleistocene phylogeographic breaks within a number of aridadapted birds (Dolman and Joseph 2015; Joseph and Wilke 2006; Kearns et al. 2009; McElroy et al. 2018; see Alpers et al. 2016 and Neaves et al. 2012 for mammalian examples). In this study, divergence across the Eyrean Barrier dated to early to mid-Pleistocene $(0.47-1.15 \mathrm{Ma})$ based on nuclear sequence data and early Pleistocene (1.02-1.71 Ma) based on mitochondrial sequence data. Bidirectional gene flow was detected across the Eyrean Barrier despite mitochondrial divergence, suggesting that male-biased dispersal might be operating. In addition, the east Australian and south-west/ central regional populations have relatively high genetic diversity and effective population sizes, suggesting that the effect of drift in these populations is low. Thus, male-biased gene flow and/or a low level of genetic drift might be responsible for the more recent inference of divergence from nuclear intron data compared with mitochondrial data. Pleistocene-dated divergence times are consistent with the estimates for two sister species of quail-thrush (Cinclosoma spp.) and diversity within the mulga parrot (Psephotellus varius) (Dolman and Joseph 2016; McElroy et al. 2018). We infer that the Eyrean Barrier drove vicariance-based phylogeographic structure of the grey shrike-thrush as inferred for many other species.

Three barriers, the Torresian Barrier, the Black Mountain Corridor and Einasleigh Uplands, are concordant with phylogeographic structure between east Australian and Cape York Peninsula/east PNG regional forms of the grey shrike-thrush. This pattern is significant for nuclear and mitochondrial genetic markers, although relatively recent mitochondrial divergence was observed. This can be explained by vicariance, followed by secondary contact and mitochondrial introgression. Other studies show extreme variation in the time of divergence across these barriers among species (see Bryant and Krosch 2016 and examples therein); divergence within a genus of evergreen trees (Elaeocarpus) dates to $0.04-0.18 \mathrm{Ma}$ while divergence within a genus of earthworm (Terrisswalkerius) dates to 31-84 Ma (Mellick et al. 2014; Moreau et al. 2015). Together with evidence of secondary contact within some relevant taxa, this indicates that multiple vicariance events have occurred across these three barriers that have had taxon-specific effects on divergence (Peñalba et al. 2017).

The Canning Barrier is reasonably inferred here as having been the driver of the mitochondrial and nuclear Pleistocene-dated phylogeographic structure between the south-west/central and north-west regional populations of grey shrike-thrush. This adds to the growing body of molecular data affirming this barrier as a Pleistocene driver of divergence (Lamb et al. 2018; Nyári and Joseph 2013). An ND6 amino acid may be evolving under positive selection in the south-west/central populations (Lamb et al. 2018), which may have further promoted divergence between the south-west/central and north-west populations.

Divergence across Bass Strait between east Australian and Tasmanian populations of grey shrike-thrush dates to $0.55-1.00 \mathrm{Ma}$ based on ND2 diversity and $0.11-0.39 \mathrm{Ma}$ based on nuclear intron diversity. These estimates predate the Last Glacial Maximum (LGM, 21 ka). This suggests that gene flow was limited between these two regions despite LGM land bridges connecting them, as has been observed for the butterfly species Heteronympha merope (Norgate et al. 2009). Marshy habitat in exposed areas during the LGM (Lambeck and Chappell 2001) would have been unsuitable for grey shrike-thrush. Male-biased gene flow may explain more recent divergence across Bass Strait of nuclear intron lineages compared with ND2 lineages. 
Slow lineage sorting of nuclear DNA is less likely here since the Tasmanian population, having relatively low effective population size and low genetic diversity, is expected to experience higher rates of genetic drift.

The few molecular studies of trans-Torres Strait species have revealed a range of patterns in historical and contemporary gene flow among regions of north Australia and the island of New Guinea (Christidis et al. 1988; Edwards 1993; Kearns et al. 2011, 2014; Roshier et al. 2012; Toon et al. 2017). Cape York Peninsula and PNG populations of grey shrike-thrush are indistinguishable based on nuclear markers. This accords with their current classification as $C . h$. superciliosa and suggests they maintained male-mediated gene flow during the LGM across then-exposed savannah woodlands and grasslands (Nix and Kalma 1972; Williams et al. 2009). Grey shrike-thrush currently inhabit savannah areas within PNG and relatively shallow divergence across Torres Strait has been repeatedly observed in savannahadapted species (Keighley et al. 2019; Murphy et al. 2007; Toon et al. 2017; Williams et al. 2008; Wüster et al. 2005) compared with deeper divergence observed in mesic closed forest-adapted species (Joseph et al. 2001; Kearns et al. 2011; Krajewski et al. 2004; Macqueen et al. 2011, 2010; Norman et al. 2007; Rawlings and Donnellan 2003; Zwiers et al. 2008). A mitochondrial lineage unique to the Trans-Fly was estimated to have diverged from mainland Australian and east PNG lineages $0.38-0.76 \mathrm{Ma}$. Distinct, albeit varyingly so, lineages have been identified within the Trans-Fly region for the eastern brown snake, the Australian magpie and the palm cockatoo (Murphy et al. 2007; Toon et al. 2017; Williams et al. 2008). The savannahs of the Trans-Fly and Central Province are separated by a markedly different zone of the Southern Lowlands of the Gulf Province with relatively high rainfall (Nix and Kalma 1972; Shearman and Bryan 2011). This zone may have acted as a driver of endemism within the Trans-Fly (Beehler and Pratt 2016; Heinsohn and Hope 2006; Kearns et al. 2011; Schodde 2006). Populations of grey shrike-thrush from the Oro and Central Provinces are indistinguishable based on nuclear and mtDNA. Though latitudinally separated by New Guinea's central Cordillera, they may have experienced recent and current connectivity via a ring of lowland forest that surrounds the Cordillera (Dumbacher and Fleischer 2001; Kearns et al. 2011).

\section{Inferences about species evolution and taxonomy}

The evolutionary history of the grey shrike-thrush appears more complex than a simple case of vicariant divergence; it has involved instances of discordant evolution of mitochondrial and nuclear DNA, asymmetric and sex-biased gene flow and apparent mitochondrial introgression. The five currently recognized subspecies of the grey shrike-thrush (New Guinean populations included in $C$. $h$. superciliosa) comprise five geographically and phylogenetically discrete clades for nuclear and mtDNA. Marki et al. (2018) identified deep divergence among the grey shrike-thrush lineages that could indicate multiple species. Compared with the rufous shrikethrush C. megarhyncha, a closely related but non-sister species, the grey shrike-thrush displays an intermediate level of intra-specific divergence: the clades of $C$. megarhyncha are much older and likely represent different species, while $C$. tenebrosa, despite being widely sampled, showed little genetic variation (Marki et al. 2018). Significant genetic differentiation, Pleistocene-dated divergence, low gene flow and few discernable phenotypic differences among the Australian mainland subspecies place the species firmly in the grey zone of speciation, i.e., different species concepts disagree on placement of species limits (De Queiroz 2007; Roux et al. 2016). It is particularly difficult to infer the trajectory of the Australian regional populations. The putative barriers implicated in their divergence are now concordant with hybrid zones between them. The Australian regional populations may have experienced isolation during the Pleistocene and could now be experiencing secondary contact, where gene flow may be either promoting uniformity or being restricted by reproductive incompatibilities (Ottenburghs et al. 2017). Testing for the presence of intrinsic genomic incompatibilities using genome-wide data may indicate whether there are barrier loci between the regional populations preventing their admixture. In addition, an analysis incorporating estimates of divergence, gene flow and $\mathrm{Ne}$ from hundreds of genome-wide markers (Hey 2009) is required to clarify the evolutionary history of grey shrike-thrush populations and to determine where they stand on the speciation continuum.

\section{Conclusions}

Pleistocene climate change has shaped the evolution of the grey shrike-thrush as it has for a diverse suite of other species. Cycles of marine transgressions and regressions and expansions and contractions of arid zones have driven divergence and sex-biased gene flow within the species. This system demonstrates that climate change can have sex-specific effects on evolution of species with different dispersal biology of sexes and this in turn has implications for the future of this and other species in our changing world. Incongruence between population and mitochondrial trees in this and other studies should trigger a genome-wide investigation into sexbiased population processes including dispersal, mitochondrial introgression and mitonuclear evolution.

\section{Data archiving}

Sequence data have been submitted to GenBank: accession numbers MH316208-MH316549 and MH472639- 
MH472641. Sequences for the aldolase B intron 4 locus $(<200$ nucleotides in length) are included in Supporting Information S2. Length-variable marker genotypes are also included in Supporting Information S2.

Acknowledgements Funding was provided by Monash University (School of Biological Sciences Women in Science Award to AP), Australian Research Council Linkage Grant (LP0776322), the Victorian Department of Environment and Primary Industries (DEPI), Museum Victoria, Parks Victoria, North Central Catchment Management Authority and Goulburn Broken Catchment Management Authority. We thank collectors of all samples used in this study and the ethics and scientific research permit agencies that allowed their collection. In particular, we thank Alex Drew and Ian Mason of ANWC for their help with collecting samples in PNG and Cape York Peninsula. We are grateful to Robert Palmer (ANWC) for curatorial assistance, Naoko Takeuchi and Maria Roitman for lab assistance, Graham Stone, James Nicholls and the UK NERC Genepool facility for sequencing support and to David Chapple and Alistair Evans for useful discussions. We also thank Gerald Heckel and the anonymous reviewers for their help in improving the quality of this manuscript. Computationally intensive analyses were performed on the Monash computer clusters courtesy of Monash eResearch.

\section{Compliance with ethical standards}

Conflict of interest The authors declare that they have no conflict of interest.

Publisher's note: Springer Nature remains neutral with regard to jurisdictional claims in published maps and institutional affiliations.

Open Access This article is licensed under a Creative Commons Attribution 4.0 International License, which permits use, sharing, adaptation, distribution and reproduction in any medium or format, as long as you give appropriate credit to the original author(s) and the source, provide a link to the Creative Commons license, and indicate if changes were made. The images or other third party material in this article are included in the article's Creative Commons license, unless indicated otherwise in a credit line to the material. If material is not included in the article's Creative Commons license and your intended use is not permitted by statutory regulation or exceeds the permitted use, you will need to obtain permission directly from the copyright holder. To view a copy of this license, visit http://creativecommons. org/licenses/by/4.0/.

\section{References}

Alpers DL, Walker FM, Taylor AC, Sunnucks P, Bellman S, Hansen BD et al. (2016) Evidence of subdivisions on evolutionary timescales in a large, declining marsupial distributed across a phylogeographic barrier. PLoS ONE 11:e0162789

Avise JC (1998) Pleistocene phylogeographic effects on avian populations and the speciation process. Proc R Soc Lond B Biol Sci 265:457-463

Avise JC (2000) Phylogeography: the history and formation of species. Harvard University Press. Cambridge, MA

Ballard JWO, Whitlock MC (2004) The incomplete natural history of mitochondria. Mol Ecol 13:729-744

Bandelt H-J, Forster P, Röhl A (1999) Median-joining networks for inferring intraspecific phylogenies. Mol Biol Evol 16:37-48
Barrows TT, Stone JO, Fifield LK, Cresswell RG (2002) The timing of the last glacial maximum in Australia. Quat Sci Rev 21:159-173

Beehler BM, Pratt TK (2016) Birds of New Guinea: distribution, taxonomy, and systematics. Princeton University Press. Princeton, New Jersey

Beerli P, Felsenstein J (2001) Maximum likelihood estimation of a migration matrix and effective population sizes in $\mathrm{n}$ subpopulations by using a coalescent approach. Proc Natl Acad Sci USA 98:4563-4568

Benjamini Y, Yekutieli D (2001) The control of the false discovery rate in multiple testing under dependency. Annals Stat 29:1165-1188

Bouckaert R, Heled J, Kühnert D, Vaughan T, Wu C-H, Xie D et al. (2014) BEAST 2: a software platform for Bayesian evolutionary analysis. PLoS Comput Biol 10:e1003537

Bowman DM, Brown G, Braby M, Brown J, Cook LG, Crisp M et al. (2010) Biogeography of the Australian monsoon tropics. J Biogeogr 37:201-216

Bryant LM, Krosch MN (2016) Lines in the land: a review of evidence for eastern Australia's major biogeographical barriers to closed forest taxa. Biol J Linn Soc 119:238-264

Byrne M, Yeates DK, Joseph L, Kearney M, Bowler J, Williams MA et al. (2008) Birth of a biome: insights into the assembly and maintenance of the Australian arid zone biota. Mol Ecol $17: 4398-4417$

Charlesworth B (2002) Effective population size. Curr Biol 12: R716-R717

Chen C, Durand E, Forbes F, François O (2007) Bayesian clustering algorithms ascertaining spatial population structure: a new computer program and a comparison study. Mol Ecol Resour 7:747-756

Chivas AR, García A, van der Kaars S, Couapel MJ, Holt S, Reeves JM et al. (2001) Sea-level and environmental changes since the last interglacial in the Gulf of Carpentaria, Australia: an overview. Quat Int 83:19-46

Christidis L, Schodde R, Baverstock PR (1988) Genetic and morphological differentiation and phylogeny in the Australo-Papuan scrubwrens (Sericornis, Acanthizidae). Auk 105:616-629

Coates BS, Sumerford DV, Miller NJ, Kim K. S, Sappington TW, Siegfried BD et al (2009) Comparative performance of single nucleotide polymorphism and microsatellite markers for population genetic analysis. Journal of Heredity 100:556-564. https:// doi.org/10.1093/jhered/esp028

De Queiroz K (2007) Species concepts and species delimitation. Syst Biol 56:879-886

Dolman G, Joseph L (2012) A species assemblage approach to comparative phylogeography of birds in southern Australia. Ecol Evol 2:354-369

Dolman G, Joseph L (2015) Evolutionary history of birds across southern Australia: structure, history and taxonomic implications of mitochondrial DNA diversity in an ecologically diverse suite of species. Emu 115:35-48

Dolman G, Joseph L (2016) Multi-locus sequence data illuminate demographic drivers of Pleistocene speciation in semi-arid southern Australian birds (Cinclosoma spp.). BMC Evolut Biol $16: 226$

Drummond AJ, Rambaut A (2007) BEAST: Bayesian evolutionary analysis by sampling trees. BMC Evolut Biol 7:214-222

Drummond AJ, Rambaut A, Shapiro B, Pybus OG (2005) Bayesian coalescent inference of past population dynamics from molecular sequences. Mol Biol Evol 22:1185-1192

Dumbacher J, Fleischer RC (2001) Phylogenetic evidence for colour pattern convergence in toxic pitohuis: Mullerian mimicry in birds? Proc R Soc B Biol Sci 268:1971-1976

Durand E, Jay F, Gaggiotti OE, François O (2009) Spatial inference of admixture proportions and secondary contact zones. Mol Biol Evol 26:1963-1973 
EdwardsSV (1993) Long-distance gene flow in a cooperative breeder detected in genealogies of mitochondrial DNA sequences. Proc R Soc Lond B Biol Sci 252:177-185

Edwards SV (2009) Natural selection and phylogenetic analysis. Proc Natl Acad Sci USA 106:8799

Eldridge MD, Potter S, Johnson CN, Ritchie EG (2014) Differing impact of a major biogeographic barrier on genetic structure in two large kangaroos from the monsoon tropics of Northern Australia. Ecol Evol 4:554-567

Excoffier L, Lischer HE (2010) Arlequin suite ver 3.5: a new series of programs to perform population genetics analyses under Linux and Windows. Mol Ecol Resour 10:564-567

Ford J (1987) Minor isolates and minor geographical barriers in avian speciation in continental Australia. Emu 87:90-102

Goudet J (2001) FSTAT, a program to estimate and test gene diversities and fixation indices. Release 2.9.3. http://www2.unil.ch/ popgen/softwares/fstat.htm

Havird JC, Sloan DB (2016) The roles of mutation, selection, and expression in determining relative rates of evolution in mitochondrial versus nuclear genomes. Mol Biol Evol 33:3042-3053

Heinsohn T, Hope G (2006) The Torresian connections: zoogeography of New Guinea. In: Evolution and Biogeography of Australian Vertebrates (eds Merrick JR, Archer M, Hickey GM, Lee MSY). Australian Scientific Publishing, Oatlands, New South Wales, pp. 71-93

Heled J, Drummond AJ (2010) Bayesian inference of species trees from multilocus data. Mol Biol Evol 27:570-580

Hewitt G (2004) Genetic consequences of climatic oscillations in the Quaternary. Philos Trans R Soc Lond B Biol Sci 359:183-195

Hey J (2009) Isolation with migration models for more than two populations. Mol Biol Evol 27:905-920

Higgins P, Peter J, eds. (2002) Vol. 6: Pardalotes to shrike-thrushes. In: Handbook of Australian, New Zealand and Antarctic Birds. Oxford University Press, Melbourne

Ho SYW, Shapiro B (2011) Skyline-plot methods for estimating demographic history from nucleotide sequences. Mol Ecol Resour 11:423-434

Jakobsson M, Rosenberg NA (2007) CLUMPP: a cluster matching and permutation program for dealing with label switching and multimodality in analysis of population structure. Bioinformatics 23:1801-1806

Jennings WB, Edwards SV (2005) Speciational history of Australian grass finches (Poephila) inferred from thirty gene trees. Evolution 59:2033-2047

Joseph L, Omland KE (2009) Phylogeography: its development and impact in Australo-Papuan ornithology with special reference to paraphyly in Australian birds. Emu 109:1-23. https://doi.org/10. 1071/MU08024

Joseph L, Slikas B, Alpers D, Schodde R (2001) Molecular systematics and phylogeography of New Guinean logrunners (Orthonychidae). Emu 101:273-280

Joseph L, Wilke T (2006) Molecular resolution of population history, systematics and historical biogeography of the Australian ringneck parrots Barnardius: are we there yet? Emu 106:49-62

Joseph L, Zeriga T, Adcock GJ, Langmore NE (2011) Phylogeography and taxonomy of the little bronze-cuckoo (Chalcites minutillus) in Australia's monsoon tropics. Emu 111:113-119

Kearns AM, Joseph L, Cook LG (2010) The impact of Pleistocene changes of climate and landscape on Australian birds: a test using the Pied Butcherbird (Cracticus nigrogularis). Emu 110:285-295

Kearns AM, Joseph L, Edwards SV, Double MC (2009) Inferring the phylogeography and evolutionary history of the splendid fairywren Malurus splendens from mitochondrial DNA and spectrophotometry. J Avian Biol 40:7-17

Kearns AM, Joseph L, Omland KE, Cook LG (2011) Testing the effect of transient Plio-Pleistocene barriers in monsoonal Australo-
Papua: did mangrove habitats maintain genetic connectivity in the Black Butcherbird? Mol Ecol 20:5042-5059

Kearns AM, Joseph L, Toon A, Cook LG (2014) Australia's aridadapted butcherbirds experienced range expansions during Pleistocene glacial maxima. Nat Commun 5:3994

Keast A (1961) Bird speciation on the Australian continent. Bull Mus Comp Zool Harv Coll 123:303-495

Keighley MV, Heinsohn R, Langmore NE, Murphy SA, Peñalba JV (2019) Genomic population structure aligns with vocal dialects in Palm Cockatoos (Probosciger aterrimus); evidence for refugial late-Quaternary distribution? Emu-Austral Ornithology 119:24-37

Krajewski C, Moyer GR, Sipiorski JT, Fain MG, Westerman M (2004) Molecular systematics of the enigmatic'phascolosoricine'marsupials of New Guinea. Aust J Zool 52:389-415

Kuhner M (2009) Coalescent genealogy samplers: windows into population history. Trends Ecol Evol 24:86-93

Lamb AM, Gan HM, Greening C, Joseph L, Lee YP, Moran-Ordonez A et al. (2018) Climate-driven mitochondrial selection: a test in Australian songbirds. Mol Ecol 27:898-918

Lambeck K, Chappell J (2001) Sea level change through the last glacial cycle. Science 292:679-686

Lanfear R, Calcott B, Ho SY, Guindon S (2012) PartitionFinder: combined selection of partitioning schemes and substitution models for phylogenetic analyses. Mol Biol Evol 29:1695-1701

Lee JY, Edwards SV (2008) Divergence across Australia's Carpentarian barrier: statistical phylogeography of the red-backed fairy wren (Malurus melanocephalus). Evolution 62:3117-3134

Leigh JW, Bryant D (2015) popart: full-feature software for haplotype network construction. Methods Ecol Evol 6:1110-1116

Lerner HR, Meyer M, James HF, Hofreiter M, Fleischer RC (2011) Multilocus resolution of phylogeny and timescale in the extant adaptive radiation of Hawaiian honeycreepers. Curr Biol 21:1838-1844

Macdonald J (1973) Birds of Australia. AH \& AW Reed, Chartswood, New South Wales, Australia

Macqueen P, Goldizen AW, Austin JJ, Seddon JM (2011) Phylogeography of the pademelons (Marsupialia: Macropodidae: Thylogale) in New Guinea reflects both geological and climatic events during the Plio-Pleistocene. J Biogeogr 38:1732-1747

Macqueen P, Seddon JM, Austin JJ, Hamilton S, Goldizen AW (2010) Phylogenetics of the pademelons (Macropodidae: Thylogale) and historical biogeography of the Australo-Papuan region. Mol Phylogenetics Evol 57:1134-1148

Marki PZ, Fjeldsa J, Irestedt M, Jonsson KA (2018) Molecular phylogenetics and species limits in a cryptically coloured radiation of Australo-Papuan passerine birds (Pachycephalidae: Colluricincla). Mol Phylogenetics Evol 124:100-105

McElroy K, Beattie K, Symonds MRE, Joseph L (2018) Mitogenomic and nuclear diversity in the Mulga Parrot of the Australian arid zone: cryptic subspecies and tests for selection. Emu - Austral Ornithol 118:22-35

Mellick R, Wilson PD, Rossetto M (2014) Demographic history and niche conservatism of tropical rainforest trees separated along an altitudinal gradient of a biogeographic barrier. Aust $\mathrm{J}$ Bot 62:438-450

Melnick DJ, Hoelzer GA (1992) Differences in male and female macaque dispersal lead to contrasting distributions of nuclear and mitochondrial DNA variation. Int J Primatol 13:379-393

Morales HE, Pavlova A, Joseph L, Sunnucks P (2015) Positive and purifying selection in mitochondrial genomes of a bird with mitonuclear discordance. Mol Ecol 24:2820-2837

Morales HE, Sunnucks P, Joseph L, Pavlova A (2017) Perpendicular axes of differentiation generated by mitochondrial introgression. Mol Ecol 26:3241-3255 
Moreau CS, Hugall AF, McDonald KR, Jamieson BG, Moritz C (2015) An ancient divide in a contiguous rainforest: Endemic earthworms in the Australian Wet Tropics. PLoS ONE 10: e0136943

Murphy SA, Double MC, Legge SM (2007) The phylogeography of palm cockatoos, Probosciger aterrimus, in the dynamic AustraloPapuan region. J Biogeogr 34:1534-1545

Neaves LE, Zenger KR, Prince RIT, Eldridge MDB (2012) Impact of Pleistocene aridity oscillations on the population history of a widespread, vagile Australian mammal, Macropus fuliginosus. J Biogeogr 39:1545-1563

Nix H, Kalma J (1972) Climate as a dominant control in the biogeography of northern Australia and New Guinea. In: Bridge and barrier: the natural and cultural history of Torres Strait (ed. Walker D). Australian National University, Canberra, pp 61-91

Norgate M, Chamings J, Pavlova A, Bull JK, Murray ND, Sunnucks P (2009) Mitochondrial DNA indicates late Pleistocene divergence of populations of Heteronympha merope, an emerging model in environmental change biology. PLoS ONE 4:e7950

Norman JA, Rheindt FE, Rowe DL, Christidis L (2007) Speciation dynamics in the Australo-Papuan Meliphaga honeyeaters. Mol phylogenetics Evol 42:80-91

Nyári ÁS, Joseph L (2013) Comparative phylogeography of AustraloPapuan mangrove-restricted and mangrove-associated avifaunas. Biol J Linn Soc 109:574-598

Ottenburghs J, Kraus RHS, van Hooft P, van Wieren SE, Ydenberg RC, Prins HHT (2017) Avian introgression in the genomic era. Avian Res 8:30. https://avianres.biomedcentral.com/articles/10. 1186/s40657-017-0088-z

Pavlova A, Amos JN, Goretskaia MI, Beme IR, Buchanan KL, Takeuchi N et al. (2012) Genes and song: genetic and social connections in fragmented habitat in a woodland bird with limited dispersal. Ecology 93:1717-1727

Pavlova A, Selwood P, Harrisson KA, Murray N, Quin B, Menkhorst $\mathrm{P}$ et al. (2014) Integrating phylogeography and morphometrics to assess conservation merits and inform conservation strategies for an endangered subspecies of a common bird species. Biol Conserv 174:136-146

Peakall R, Smouse PE (2006) GENALEX 6: genetic analysis in Excel. Population genetic software for teaching and research. Mol Ecol Notes 6:288-295

Peñalba JV, Mason IJ, Schodde R, Moritz C, Joseph L (2017) Characterizing divergence through three adjacent Australian avian transition zones. J Biogeogr 4:2247-2258

Potter S, Eldridge MD, Taggart DA, Cooper SJ (2012) Multiple biogeographical barriers identified across the monsoon tropics of northern Australia: phylogeographic analysis of the brachyotis group of rock-wallabies. Mol Ecol 21:2254-2269

QGIS Development Team (2017) QGIS geographic information system. Open source geospatial foundation project. Release 2.14.3. http://qgis.osgeo.org/

Rambaut A (2014) FigTree software. Institute of Evolutionary Biology, University of Edinburgh. Release 1.4.2. http://tree.bio.ed.ac. uk/software/figtree/

Rambaut A, Drummond A (2007) Tracer. Release 1.4. http://tree.bio. ed.ac.uk/software/tracer/

Rawlings LH, Donnellan SC (2003) Phylogeographic analysis of the green python, Morelia viridis, reveals cryptic diversity. Mol phylogenetics Evol 27:36-44

Raymond M, Rousset F (2004) GENEPOP: population genetics software for exact tests and ecumenicism. Release 3.4. Available from: http://genepop.curtin.edu.au/
Roshier DA, Heinsohn R, Adcock GJ, Beerli P, Joseph L (2012) Biogeographic models of gene flow in two waterfowl of the Australo-Papuan tropics. Ecol Evol 2:2803-2814

Roux C, Fraisse C, Romiguier J, Anciaux Y, Galtier N, Bierne N (2016) Shedding light on the grey zone of speciation along a continuum of genomic divergence. PLoS Biol 14:e2000234

Rozas J, Ferrer-Mata A, Sánchez-DelBarrio JC, Guirao-Rico S, Librado P, Ramos-Onsins SE et al. (2017) DnaSP 6: DNA sequence polymorphism analysis of large data sets. Mol Biol Evol 34:3299-3302

Schodde R (2006) Australia's bird fauna today-origins and development. In: Evolution and Biogeography of Australasian Vertebrates (eds Merrick JR, Archer M, Hickey GM, Lee MSY), pp. 413-458. AusciPub, Sydney

Schodde R, Mason I (1999). Vol. 2. Passerines. In: Directory of Australian birds. CSIRO Publishing, Melbourne

Schweizer M, Guentert M, Hertwig ST (2013) Out of the Bassian province: historical biogeography of the Australasian platycercine parrots (Aves, Psittaciformes). Zool Scr 42:13-27

Shearman P, Bryan J (2011) A bioregional analysis of the distribution of rainforest cover, deforestation and degradation in Papua New Guinea. Austral Ecol 36:9-24

Stephens M, Donnelly P (2003) A comparison of bayesian methods for haplotype reconstruction from population genotype data. Am J Hum Genet 73:1162-1169

Sunnucks P, Morales HE, Lamb AM, Pavlova A, Greening C (2017) Integrative approaches for studying mitochondrial and nuclear genome co-evolution in oxidative phosphorylation. Front Genet 8:25

Toews DP, Brelsford A (2012) The biogeography of mitochondrial and nuclear discordance in animals. Mol Ecol 21:3907-3930

Toon A, Drew A, Mason IJ, Hughes JM, Joseph L (2017) Relationships of the New Guinean subspecies, Gymnorhina tibicen papuana, of the Australian Magpie: an assessment from DNA sequence data. Emu-Austral Ornithol 17:305-315

Toon A, Hughes J, Joseph L (2010) Multilocus analysis of honeyeaters (Aves: Meliphagidae) highlights spatio-temporal heterogeneity in the influence of biogeographic barriers in the Australian monsoonal zone. Mol Ecol 19:2980-2994

Torgersen T, Luly J, De Deckker P, Jones MR, Searle DE, Chivas AR et al. (1988) Late quaternary environments of the Carpentaria Basin, Australia. Palaeogeogr, Palaeoclimatol, Palaeoecol 67:245-261

Williams DJ, O'Shea M, Daguerre RL, Pook CE, Wuester W, Hayden CJ et al. (2008) Origin of the eastern brownsnake, Pseudonaja textilis (Duméril, Bibron and Duméril)(Serpentes: Elapidae: Hydrophiinae) in New Guinea: evidence of multiple dispersals from Australia, and comments on the status of Pseudonaja textilis pughi Hoser 2003. Zootaxa 1703:47-61

Williams M, Cook E, van der Kaars S, Barrows T, Shulmeister J, Kershaw P (2009) Glacial and deglacial climatic patterns in Australia and surrounding regions from 35000 to 10000 years ago reconstructed from terrestrial and near-shore proxy data. Quat Sci Rev 28:2398-2419

Wüster W, Dumbrell AJ, Hay C, Pook CE, Williams DJ, Fry BG (2005) Snakes across the Strait: trans-Torresian phylogeographic relationships in three genera of Australasian snakes (Serpentes: Elapidae: Acanthophis, Oxyuranus, and Pseudechis). Mol Phylogenetics Evol 34:1-14

Zwiers PB, Borgia G, Fleischer RC (2008) Plumage based classification of the bowerbird genus Sericulus evaluated using a multi-gene, multi-genome analysis. Mol phylogenetics Evol 46:923-931 